\title{
Health-related quality of life and 6 min walk distance in patients with idiopathic pulmonary fibrosis
}

\author{
Geetika Verma MD MPH${ }^{1}$, Theodore Marras MD MSc${ }^{2}$, Noori Chowdhury MSc MPH${ }^{3}$, Lianne Singer MD
}

G Verma, T Marras, N Chowdhury, L Singer. Health-related quality of life and 6 min walk distance in patients with idiopathic pulmonary fibrosis. Can Respir J 2011;18(5):283-287.

BACKGROUND: Few studies have investigated the relationship between physiological outcomes and quality of life in patients with idiopathic pulmonary fibrosis (IPF). Health-related quality of life (HRQL) data may provide a valuable patient-centred outcome for the evaluation of interventions. Determination of which physiological and functional variables are associated with HRQL may facilitate interpretation of disease progression and impacts of therapy.

OBJECTIVES: To determine whether an association between Medical Outcomes Short-Form 36 and St George's Respiratory Questionnaire scores and other markers of disease severity exist, and to identify which physiological and functional variables are independently associated with HRQL.

METHODS: In a cross-sectional study, 137 patients with IPF completed HRQL surveys and underwent clinical assessment. Multiple linear regression analysis was used to determine the relationship between age, forced vital capacity, diffusing capacity of carbon monoxide, 6 min walk distance (6MWD) and oxygen requirement, and HRQL scores.

RESULTS: 6MWD was the only functional measure of disease severity significantly associated with all domain scores of the St George's Respiratory Questionnaire and the Medical Outcomes Short-Form 36 physical component summary score.

CONCLUSIONS: 6MWD was associated with HRQL among patients with IPF. This highlights the importance of 6MWD not only as a prognostic indicator in IPF, but also a predictor of HRQL and a meaningful outcome for patients.

Key Words: 6MWD; Idiopathic pulmonary fibrosis; Quality of life

diopathic pulmonary fibrosis (IPF) carries a poor prognosis and, to date, no therapies have been shown to alter mortality. Aside from the predictably high mortality rate of the disease, the morbidity associated with the typical course of IPF has a broad and profound impact on the patient's ability to function without supplemental oxygen or significant disability. Health-related quality of life (HRQL) may be an important and meaningful treatment outcome for patients, particularly because no treatment has been shown to impact survival. Furthermore, many available treatments confer serious side effects, suggesting that there is a significant trade-off involved in undertaking such treatment. Recent clinical trials for IPF have included some evaluation of HRQL, although no therapies have shown a positive impact on HRQL (1-5). However, only a few studies have examined HRQL as a primary end point in the IPF population (6-15). Further investigation of the impact of IPF on HRQL, and the association of HRQL with other markers of disease severity, may shed light on whether current and future treatments provide improvements in outcomes that are meaningful to patients.

\section{La qualité de vie liée à la santé et le test de marche de six minutes chez les patients atteints de fibrose pulmonaire idiopathique}

HISTORIQUE : Peu d'études ont porté sur le lien entre les issues physiologiques et la qualité de vie chez les patients atteints de fibrose pulmonaire idiopathique (FPI). Les données sur la qualité de vie liée à la santé (QVLS) peuvent fournir de précieux résultats axés sur le patient pour évaluer les interventions. La détermination des variables physiologiques et fonctionnelles qui s'associent à la QVLS peut faciliter l'interprétation de l'évolution de la maladie et les répercussions de la thérapie.

OBJECTIFS : Déterminer s'il y a une association entre les indices du formulaire court sur les issues médicales en 36 questions ainsi que le questionnaire respiratoire de St George et d'autres marqueurs de gravité de la maladie, et établir quelles variables physiologiques et fonctionnelles s'associent de manière indépendante à la QVLS.

MÉTHODOLOGIE : Dans une étude transversale, 137 patients atteints de FPI ont rempli les questionnaires de la QVLS et ont subi une évaluation clinique. Une analyse de régression linéaire multiple était utilisée pour déterminer le lien entre l'âge, la capacité vitale forcée, la capacité de diffusion du monoxyde de carbone, le test de marche de six minutes (TM6M) et les besoins en oxygène ainsi que les indices de QVLS.

RÉSULTATS : Le TM6M était la seule mesure fonctionnelle de gravité de la maladie à s'associer de manière significative à tous les indices de domaine du questionnaire respiratoire de St George et à l'indice sommaire du volet physique du formulaire court sur les issues médicales en 36 questions.

CONCLUSIONS : Le TM6M s'associait à la QVLS chez les patients atteints de FPI. Ce constat fait ressortir l'importance du TM6M non seulement à titre d'indicateur pronostique de la FPI, mais également de prédicteur de la QVLS et d'issue significative chez les patients.

In the present cross-sectional study, we measured HRQL using the Medical Outcomes Short-Form 36 (SF-36) and the St George's Respiratory Questionnaire (SGRQ) among 137 IPF patients. The Medical Outcomes SF-36 is a generic HRQL measure that may be used in a variety of medical conditions. It is a health profile consisting of eight scales (general health, physical functioning, role physical, bodily pain, social functioning, role emotional, vitality and mental health) as well as psychometrically based summary measures of physical and mental health (the physical component summary [PCS] and the mental component summary [MCS]) that aggregate the scales $(16,17)$. The SGRQ is a respiratory disease-specific HRQL tool originally developed for chronic obstructive lung disease and consists of three components (symptoms, activity and impacts) as well as a total score (18). These tools were selected based on previous studies demonstrating their validity in this setting $(7-16)$ and their common use in therapeutic trials involving patients with $\operatorname{IPF}(1,2,4-6)$. Our hypothesis was that IPF patients experience important decrements in HRQL, and that these would be associated with reductions in conventional physiological or functional outcome measures.

${ }^{1}$ University of Alberta, Edmonton, Alberta; ${ }^{2}$ University of Toronto; ${ }^{3}$ Toronto General Research Institute, University Health Network;

${ }^{4}$ University of Toronto, University Health Network, Toronto, Ontario

Correspondence: Dr Geetika Verma, University of Alberta, 8329-11402 Univetsity Avenue, Edmonton, Alberta T6G 1G1.

Telephone 780-407-1348, fax 780-407-1429, e-mail gverma@ualberta.ca 
TABLE 1

\section{Patient characteristics}

\begin{tabular}{lrc}
\hline Variable, $\mathbf{n}$ & $\mathbf{n}$ & Mean \pm SD (range) \\
\hline Age, years & 137 & $59.4 \pm 7.1(38-74)$ \\
Sex, $\mathrm{n} / \mathrm{n}(\%)$ & 137 & $90 / 137$ male $(65.7)$ \\
FEV $_{1}, \%$ predicted & 135 & $68.0 \pm 19.8(18.8-129.3)$ \\
FVC, \% predicted & 135 & $61.7 \pm 19.8(24.5-126.5)$ \\
TLC, \% predicted & 113 & $67.7 \pm 16.0(41.2-122.7)$ \\
DLCO, \% predicted & 91 & $49.5 \pm 17.9(16.0-94.0)$ \\
6 min walk test distance, $\mathrm{m}$ & 132 & $336.4 \pm 124.4(92.0-578.0)$ \\
RVSP, mmHg & 120 & $46.1 \pm 14.7(21.0-100.0)$ \\
Prednisone used, n/n (\%) & 137 & $64 / 137(46.7)$ \\
Supplemental oxygen used, n/n (\%) & 137 & $99 / 137(72.3)$ \\
Listed for transplant, $\mathrm{n} / \mathrm{n}(\%)$ & 137 & $34 / 137(24.8)$
\end{tabular}

DLCO Diffusing capacity for carbon monoxide; FEV 1 Forced expiratory volume in $1 \mathrm{~s}$; FVC Forced vital capacity; RVSP Right ventricular systolic pressure; TLC Total lung capacity

\section{METHODS}

Patients were recruited through the Lung Transplant and the Interstitial Lung Disease clinics at the University Health Network in Toronto (Ontario) between November 2003 and March 2008. Adult patients were eligible if they met the American Thoracic Society criteria for the diagnosis of IPF (19) and were sufficiently proficient in English to complete the HRQL surveys. Exclusion criteria included connective tissue disease or interstitial lung diseases other than IPF determined on the basis of clinical records, open lung biopsy or serological markers of connective tissue disease. Patients provided written consent, and ethics approval was obtained from the University Health Network Research Ethics Board.

Web-based versions of the SF-36 and the SGRQ were used to measure HRQL. These were completed initially in the presence of a research assistant who provided technical assistance, but no coaching regarding patient responses. Web-based versions of the SF-36 have been previously validated (20). While SF-36 component summary scores were normalized to a mean $( \pm$ SD) of $50 \pm 10$, the eight SF-36 domain scores were not normalized (21). When the computerized version of the SGRQ was compared with the standard paper version, the mean difference between total scores was -0.6 units, which was not statistically significant (data not shown).

HRQL measurements were made within three months of routine clinical assessment and included spirometry, plethysmography, $6 \mathrm{~min}$ walk test and echocardiographic assessment of right ventricular systolic pressure (RVSP). Pulmonary function and 6 min walk tests were performed using the Medisoft spirometry system and plethysmograph (Medisoft Cardio-respiratory Instrumentation, Belgium) in accordance with American Thoracic Society guidelines (22-25). Equations by Gaensler and Smith (26), and Morris et al (27), respectively, were used to calculate the diffusing capacity for carbon monoxide (DLCO, $\mathrm{mL} / \mathrm{min} / \mathrm{mmHg}$ ), total lung capacity, forced expiratory volume in $1 \mathrm{~s}$ and forced vital capacity (FVC) per cent predicted. Patients who already had an oxygen prescription used their usual inspired oxygen during the 6 min walk test.

Scatter plots were used to ensure linear relationships. Bivariate linear regression was performed to determine the relationship between the SF-36 PCS and MCS, and each domain of the SGRQ with age, sex, pulmonary function, $6 \mathrm{~min}$ walk test distance (6MWD) and RVSP, and oxygen requirement.

For the multivariable analyses, variables with $\mathrm{P} \leq 0.2$ on bivariate analysis were included, and age was forced into the model because of its potential influence on HRQL (28). Multiple linear regression models were used to evaluate the relationship between HRQL scores and five independent parameters (age, 6MWD, FVC and DLCO per cent predicted and oxygen requirement). All independent variables were treated as continuous with the exception of oxygen requirement,
TABLE 2

Medical Outcomes Short Form-36 (SF-36) scores ( $n=137)$

\begin{tabular}{llcc}
\hline SF-36 & Mean (range) & 95\% Cl & $\begin{array}{c}\text { Canadian } \\
\text { population } \\
\text { norm* }\end{array}$ \\
\hline Physical functioning & $25.6(0-100)$ & $21.9-29.4$ & 82.3 \\
Role physical & $31.0(0-100)$ & $26.9-35.1$ & 81.3 \\
Bodily pain & $68.0(0-100)$ & $63.4-72.7$ & 74.9 \\
General health & $35.5(0-97)$ & $31.9-39.0$ & 74.8 \\
Vitality & $39.3(0-87.5)$ & $35.8-42.9$ & 68.3 \\
Social functioning & $59.2(0-100)$ & $54.05-64.38$ & 88.1 \\
Role emotional & $74.5(0-100)$ & $69.6-79.3$ & 87.8 \\
Mental health & $71.2(0-100)$ & $67.9-74.6$ & 79.5 \\
Physical component & $29.4(6.4-58.4)$ & $27.9-30.9$ & 49.0 \\
$\quad$ summary & & & \\
Mental component & $49.7(12.8-74.4)$ & $47.6-51.7$ & 53.7 \\
$\quad$ summary & & & \\
*55 to 64 years of age (29) & & &
\end{tabular}

which was dichotomous. Missing patient data for one or more variables resulted in exclusion of the patient from the multivariable analysis.

It was decided that a minimum sample of 50 patients was required to evaluate the five independent variables in the multiple linear regression model, based on the assumption that one predictor variable can be studied for every 10 subjects for whom there are observations, and still avoid overfitting (29). $\mathrm{P}<0.05$ was considered to be clinically significant for all analyses. All statistical analyses were performed using SAS version 9.1 (SAS Institute Inc, USA).

\section{RESULTS}

A total of 239 pretransplant patients with interstitial lung disease were considered for inclusion in the study. Ninety-two patients were excluded due to the possibility of a diagnosis of interstitial lung disease other than IPF or comorbid connective tissue disease. Six patients declined participation and four could not participate due to language barriers. A total of 137 patients with IPF completed HRQL surveys and clinical assessment.

The characteristics of these patients are summarized in Table 1. Most patients were men, with an average age of 59 years (range 38 to 74 years of age). At the time of assessment, 34 patients were listed for lung transplant, 84 were undergoing assessment for possible lung transplant, three were referred for assessment and the remaining 16 were not referred to the transplant service. Forty-seven per cent of patients had used prednisone and $72 \%$ were prescribed supplemental oxygen. On average, the patients had moderate pulmonary function impairment, although this ranged from mild to severe restrictive disease.

Patient scores on the Medical Outcomes SF-36 demonstrated greater impairment on the domains reflecting physical functioning, such as physical functioning, role physical and PCS (Table 2). The general health and vitality domains also reflected significant impairment, whereas patient scores were higher for the mental health domains (such as role emotional, mental health and MCS). The bodily pain scores were also relatively high in this population, suggesting that pain was not a major factor affecting HRQL in the patients with IPF. Compared with Canadian normative scores, patient scores were low in all domains except mental health and the MCS (30).

For the SGRQ, higher scores reflect greater impairment (Table 3). The patients scored highest on the activity domain. All of the symptoms, activity, impacts and total scores reflected impairment in the study population; they also reflected severe impairment compared with age-matched population norms (28).

In the bivariate analysis, per cent predicted FVC correlated significantly with SGRQ activity, impacts and total scores, as well as the SF-36 PCS score. 6MWD was significantly correlated with all 
components of the SGRQ and both the PCS and MCS of the SF-36. DLCO per cent predicted correlated with SGRQ activity, impacts and total score. The need for supplemental oxygen correlated with SGRQ activity and total scores, as well as the SF-36 PCS score. Age, sex and echocardiographic estimation of RVSP did not correlate significantly with any HRQL scores. Multiple linear regression analysis was performed including age, FVC (per cent predicted), DLCO (per cent predicted), 6MWD and oxygen requirement as independent variables for each domain and total scores of the two HRQL instruments. The results for the SGRQ symptoms, activity, impacts and total score, and the SF-36 PCS and MCS are summarized in Tables 4 and 5. Only 6MWD was significantly associated with all SGRQ domain scores and the SF-36 PCS score after adjusting for the other independent variables. Supplemental oxygen requirement was associated with the SF-36 MCS score $(\mathrm{P}=0.0123[\mathrm{n}=82])$. Despite the finding of no bivariate association between RVSP and HRQL, the multivariate analyses were repeated, including RVSP estimated by echocardiogram as an independent variable, which had no impact on the overall results $(\mathrm{n}=74$, analysis not shown). Baseline characteristics and HRQL scores for patients with complete data versus 55 patients with incomplete data who were excluded from the multivariable analysis using $t$ tests were compared. Most patients completed the 6 min walk test (132 of 137), but had missing data for DLCO. The patients who were excluded had significantly higher SGRQ activity, impacts and total scores, and lower SF-36 PCS scores $(\mathrm{P}<0.05)$.

\section{DISCUSSION}

Our study included a sample of exclusively IPF patients that was large enough to perform multivariable analysis to assess which physiological and functional variables were significantly associated with HRQL. Our analysis indicated that the relationship between 6MWD and HRQL is stronger than that for any other conventional measure of disease severity in IPF.

Many studies have attempted to highlight clinical and physiological parameters that best correlate with histology or are associated with a worse prognosis in IPF. To date, there has been little emphasis on HRQL in patients with IPF, although it is increasingly monitored in clinical trials. With no IPF disease-specific instrument, there is a need for additional investigation of the validity and responsiveness of the existing instruments in patients with $\operatorname{IPF}(8,10)$. A variety of generic and disease-specific HRQL tools have been used in interstitial lung disease: two generic indexes - the Medical Outcomes SF-36 and the WHO-QOL 100 - and the respiratory disease-specific SGRQ (7,8,11-15). However, most of these studies are limited by a small sample size, which may account for some discordant results. Despite these limitations, construct validity of both the SF-36 and the SGRQ in IPF patients has been demonstrated in previous studies and was supported in our study. These instruments have also been used as a means of following HRQL in clinical trials for IPF $(1,2,4-6)$. To our knowledge, our study is the largest that examined as its primary end point the relationship between HRQL scores from both a generic index and a respiratory-specific tool with physiological and clinical parameters commonly measured in patients with IPF. Our study lends additional validity to the use of these two HRQL instruments in the setting of IPF.

In our study, 6MWD had a strong, independent association with the PCS of the SF-36, as well as all domain scores and the total score for the SGRQ. Tomioka et al (7) evaluated the SF-36 in 46 patients with IPF. They found that 6MWD, vital capacity and lowest oxygen saturation during the 6 min walk test were correlated with SF-36 scores. Chang et al (15) also found a strong correlation between 6MWD and both SGRQ score and SF-36 PCS among 50 patients with interstitial lung disease, although not necessarily IPF. The consistency of these two studies with our results strengthens the association observed between 6MWD and HRQL.

As might be expected from previous reports $(7,11,13,15)$, we also confirmed significant bivariate associations between HRQL and other

\section{TABLE 3}

St George's Respiratory Questionnaire (SGRQ) scores

\begin{tabular}{llcc}
\hline SGRQ & Mean (range) & 95\% Cl & Population norm $^{*}$ \\
\hline Symptoms & $59.8(0-97.2)$ & $56.2-63.4$ & 16.1 \\
Activity & $81.6(6.0-99.5)$ & $78.7-84.4$ & 16.3 \\
Impacts & $54.1(0-96.4)$ & $50.6-57.6$ & 8.1 \\
Total & $63.4(3.7-96.3)$ & $60.4-66.3$ & 12.2 \\
\hline
\end{tabular}

*60 to 69 years of age (27)

clinical parameters including FVC, DLCO and the need for supplemental oxygen. However, all of these parameters tend to worsen in parallel as IPF progresses. The larger number of patients in our study enabled us to perform multivariate analysis to distinguish the relative impact of these factors on HRQL. We found that FVC was no longer significantly associated with HRQL after adjustment for other variables. Although low and worsening FVC has been shown to be a poor prognostic sign in observational studies $(31,32)$, our findings suggest that small differences in FVC are not associated with meaningful differences in HRQL. In contrast, 6MWD consistently showed robust associations with all SGRQ domain and total scores, and the PCS of the SF36. This would suggest that the 6MWD is the best clinical predictor of HRQL. Possible explanations for the lack of independent association between DLCO and HRQL may include the difficulty in measuring DLCO as disease progresses, and that its impairment may, in part, be corrected by supplemental oxygen. Furthermore, variables such as DLCO and FVC are purely physiological and, therefore, may not be as closely associated with HRQL as functional measures.

While oxygen requirement was also associated with HRQL, this association was limited to the MCS of the SF-36. Overall associations between mental health scores and physiological parameters were weak, and significant associations existed only with measures of physical functioning. It may be that the need for supplemental oxygen in IPF captures an aspect of HRQL that physiological measurements do not. Chang et al (15) also found a significant association between HRQL and the need for supplemental oxygen. The consistent finding of the need for supplemental oxygen and worsening HRQL is understandable, although there are limited data regarding this relationship.

There has been increasing attention paid to pulmonary hypertension in IPF and its impact on outcomes in IPF patients (33). In our study, RVSP did not have a significant relationship with HRQL scores. This likely relates, in part, to the limitations of echocardiographic estimation of RVSP as a measure of pulmonary hypertension. Based on our results, there is little correlation between echocardiographically defined pulmonary hypertension and HRQL in pateints with IPF.

We did not assess longitudinal physiological and HRQL information in our patients, and there is scarce published work that has done so. Tomioka et al (7) evaluated the SF-36 longitudinally in a subset of 32 patients with IPF. The SF-36 was responsive to changes in vital capacity, changes in DLCO and changes in the lowest oxygen saturation with 6 min walk test, but not the actual 6MWD. A recent phase II study examining the effects of etanercept in 88 patients with IPF (34) found that both change in FVC and 6MWD were significantly correlated with the SF-36 PCS and SGRQ scores in the 48-week follow-up period. Swigris et al (35) used data from the randomized placebo-controlled trial of bosentan in idiopathic pulmonary fibrosis (BUILD-1) to derive a minimum clinically important distance (MCID) in 6MWD. There was a statistically significant relationship observed between change in 6MWD and change in SGRQ total score, and the calculated MCID in the 6MWD was $28 \mathrm{~m}$ (range $11 \mathrm{~m}$ to $59 \mathrm{~m}$ ). These authors also used the data from BUILD-1 to derive MCID estimates for both the SF-36 and the SGRQ for IPF patients (36). They found that subjects whose clinical status had changed the most had the greatest change in both SF-36 and SGRQ scores, lending validity to these two instruments in this population. However, a relatively small proportion of subjects actually experienced a change in clinical status during the 
TABLE 4

Multiple linear regression analysis for SGRQ symptoms, activities and impacts (number of observations = 82)

\begin{tabular}{|c|c|c|c|c|}
\hline \multirow[b]{2}{*}{ Variable } & \multicolumn{4}{|c|}{ Regression coefficient (95\% Cl); P } \\
\hline & Symptoms & Activities & Impacts & Total \\
\hline Age & $-0.64(-1.28$ to 0.008$) ; 0.053$ & $-0.18(-0.68$ to 0.31$) ; 0.46$ & $-0.43(-1.06$ to 0.20$) ; 0.18$ & $-0.39(-0.90$ to 0.12$) ; 0.14$ \\
\hline FVC (\% predicted) & $-0.15(-0.40$ to 0.10$) ; 0.24$ & $-0.15(-0.34$ to 0.04$) ; 0.13$ & $-0.16(-0.40$ to 0.09$) ; 0.20$ & $-0.15(-0.35$ to 0.05$) ; 0.13$ \\
\hline 6MWD & $-0.05(-0.10$ to -0.005$) ; \mathbf{0 . 0 3 0}$ & $-0.07(-0.10$ to -0.03$) ; \mathbf{0 . 0 0 0 3}$ & $-0.07(-0.11$ to -0.03$) ; \mathbf{0 . 0 0 2}$ & $-0.07(-0.10$ to -0.03$) ; \mathbf{0 . 0 0 0 5}$ \\
\hline Supplemental oxygen & $1.50(-9.4$ to 12.4$) ; 0.79$ & $3.82(-4.6$ to 12.2$) ; 0.37$ & $-2.73(-13.4$ to 8.0$) ; 0.61$ & $-0.04(-8.76$ to 8.67$) ; 0.99$ \\
\hline DLCO (\% predicted) & $0.004(-0.29$ to 0.30$) ; 0.98$ & $-0.14(-0.37$ to 0.08$) ; 0.21$ & $-0.12(-0.40$ to 0.17$) ; 0.42$ & $-0.11(-0.34$ to 0.13$) ; 0.38$ \\
\hline
\end{tabular}

$P$ values in bold indicate statistical significance. $6 M W D 6$ min walk distance; DLCO Diffusing capacity for carbon monoxide; FVC Forced vital capacity; SGRQ St George's Respiratory Questionnaire

\begin{tabular}{|c|c|c|}
\hline \multirow[b]{2}{*}{ Variable } & \multicolumn{2}{|c|}{ Regression coefficient (95\% Cl); P } \\
\hline & MCS & PCS \\
\hline Age & $-0.04(-0.39$ to 0.32$) ; 0.84$ & 0.21 (-0.07 to 0.49$) ; 0.14$ \\
\hline FVC, \% predicted & 0.13 (-0.009 to 0.26$) ; 0.07$ & 0.05 (-0.06 to 0.16$) ; 0.38$ \\
\hline 6MWD & $0.02(-0.009$ to 0.04$) ; 0.21$ & 0.03 (0.01 to 0.05 ); $\mathbf{0 . 0 0 1}$ \\
\hline $\begin{array}{l}\text { DLCO, } \\
\% \text { predicted }\end{array}$ & $0.08(-0.08$ to 0.24$) ; 0.33$ & $-0.03(-0.15$ to 0.10$) ; 0.66$ \\
\hline $\begin{array}{l}\text { Supplemental } \\
\text { oxygen }\end{array}$ & 8.26 (2.30 to 14.23 ); $\mathbf{0 . 0 0 7}$ & -1.18 (-5.88 to 3.52$) ; 0.62$ \\
\hline
\end{tabular}

$P$ values in bold indicate statistical significance. 6MWD 6 min walk distance; DLCO Diffusing capacity for carbon monoxide; FVC Forced vital capacity

study period, which limited the number of subjects included in these estimates. Additional data are needed to better understand the relationship between longitudinal physiological and HRQL measurements in IPF.

There was evidence of floor and ceiling effects in the HRQL data from our subjects (data not shown). With the SF-36, many patients $(n=124)$ responded with a maximum score. The majority of these maximum scores occurred in the domains of bodily pain, role emotional and social functioning. The mean scores of our patients were not significantly different from Canadian population norms in the domains of bodily pain and role emotional, indicating that our population did not have significant HRQL impairments in these categories. Many patients $(n=59)$ also had minimum scores in some domains of the SF-36, mainly in role physical $(n=20)$ and physical functioning $(n=13)$. Only two respondents had a score of 0 (best possible) in any of the SGRQ domains, and there were no 'floor' or minimum score responses to the SGRQ. This difference may indicate that the respiratory disease-specific tool domains better reflected HRQL in our population, with few respondents indicating no impairment in some domains and maximum impairment in others. These data also suggest that the SGRQ may be a more responsive HRQL index for patients with IPF.

Our study has some potentially important implications. It lends further support of the association between physiological measures and HRQL, most notably 6MWD. Establishing the importance of 6MWD as a predictor of HRQL highlights the relevance of its routine measurement. Furthermore, this knowledge may help to focus interventions on maximizing HRQL.

Our study had several limitations. First, most of the patients enrolled had already been referred for transplant. This may impact the generalizability to patients who are too early in their disease course for transplant referral, or who may be too elderly or have comorbidities that preclude transplant referral. However, we attempted to eliminate patients with significant comorbidities due to the impact they would have on HRQL. Furthermore, because IPF patients are referred for transplant relatively early in their disease course, they do not necessarily represent an extreme of disease severity. Patients referred for transplant may be more motivated or optimistic, which may impact HRQL scores. Based on the lung function values, we believe that our study population was representative of a reasonable spectrum of moderate to severe IPF. Compared with the patients in both the etanercept and bosentan studies, our patients were younger and had slightly worse lung physiology $(5,6)$.

Second, we were unable to examine dyspnea scores in our population because they had not been collected systematically. Dyspnea has been correlated with HRQL in previous studies, more so than other physiological measures $(12,13,15)$. While our sample size was larger than most studies examining HRQL in IPF patients, incomplete data in fields including DLCO limited the number of patients included in the multivariable analysis to 82 . Furthermore, patients who had missing data had poorer HRQL scores. This is likely explained by the fact that more severe disease can interfere with the ability to undergo diffusing capacity assessment. Finally, the cross-sectional design of the present study does not enable the evaluation of responsiveness of these HRQL tools in IPF and change in HRQL among patients with IPF over time. It would be important to evaluate HRQL prospectively in a sufficiently large sample to determine longitudinal relationships between functional status and HRQL, and to substantiate the findings of the present study.

\section{CONCLUSION,}

The present study evaluated the HRQL of patients with IPF using the SF-36 and the SGRQ. HRQL was significantly impaired in this group of IPF patients. HRQL scores had a strong correlation with 6MWD. Additional work should be performed to identify minimally important differences in functional and physiological measurements, in both cross-sectional and longitudinal datasets. HRQL is an important outcome to consider in patients with IPF, and additional research should focus on identifying meaningful end points for those with this devastating disease.

\section{REFERENCES}

1. Azuma A NT, Tsuboi E, Suga M, et al. Double-blind, placebocontrolled trial of pirfenidone in patients with idiopathic pulmonary fibrosis. Am J Respir Crit Care Med 2005;171:1040-7.

2. Demedts M, Behr J, Buhl R, et al. High-dose acetylcysteine in idiopathic pulmonary fibrosis. N Engl J Med 2005;353:2229-42.

3. Douglas WW, Ryu JH, Swensen SJ, et al. Colchicine versus prednisone in the treatment of idiopathic pulmonary fibrosis. A randomized prospective study. Members of the Lung Study Group. Am J Respir Crit Care Med 1998;158:220-5.

4. Raghu G, Brown KK, Bradford WZ, et al. A placebo-controlled trial of interferon gamma- $1 \mathrm{~b}$ in patients with idiopathic pulmonary fibrosis. N Engl J Med 2004;350:125-33.

5. King TE Jr, Behr J, Brown KK, et al. BUILD-1: A randomized placebo-controlled trial of bosentan in idiopathic pulmonary fibrosis. Am J Respir Crit Care Med 2008;177:75-81.

6. Raghu G, Brown KK, Costabel U, et al. Treatment of idiopathic pulmonary fibrosis with etanercept: An exploratory, placebo-controlled trial. Am J Respir Crit Care Med 2008;178:948-55.

7. Tomioka H, Imanaka K, Hashimoto K, Iwasaki H. Health-related quality of life in patients with idiopathic pulmonary fibrosis cross-sectional and longitudinal study. Intern Med 2007;46:1533-42. 
8. Swigris JJ, Stewart AL, Gould MK, Wilson SR.

Patients' perspectives on how idiopathic pulmonary fibrosis affects the quality of their lives. Health Qual Life Outcomes 2005;3:61.

9. Swigris JJ, Kuschner WG, Jacobs SS, Wilson SR, Gould MK. Health-related quality of life in patients with idiopathic pulmonary fibrosis: A systematic review. Thorax 2005;60:588-94.

10. Swigris JJ, Gould MK, Wilson SR. Health-related quality of life among patients with idiopathic pulmonary fibrosis. Chest 2005;127:284-94.

11. Ohno S, Nakazawa S, Kobayashi A, Bando M, Sugiyama Y. Reassessment of the classification of the severity in idiopathic pulmonary fibrosis using SF-36 questionnaire. Intern Med 2005;44:196-9.

12. Nishiyama $\mathrm{O}$, Taniguchi $\mathrm{H}$, Kondoh $\mathrm{Y}$, et al. Health-related quality of life in patients with idiopathic pulmonary fibrosis. What is the main contributing factor? Respir Med 2005;99:408-14.

13. Martinez TY, Pereira CA, dos Santos ML, Ciconelli RM, Guimaraes SM, Martinez JA. Evaluation of the short-form 36-item questionnaire to measure health-related quality of life in patients with idiopathic pulmonary fibrosis. Chest 2000;117:1627-32.

14. De Vries J, Kessels BL, Drent M. Quality of life of idiopathic pulmonary fibrosis patients. Eur Respir J 2001;17:954-61.

15. Chang JA, Curtis JR, Patrick DL, Raghu G. Assessment of health-related quality of life in patients with interstitial lung disease. Chest 1999;116:1175-82.

16. McHorney CA WJJ, Raczek AE. The MOS 36-item Short-Form Health Survey (SF-36): II. Psychometric and clinical tests of validity in measuring physical and mental health constructs. Med Care 1993;31:247-63.

17. McHorney CA WJJ, Lu JF, Sherbourne CD. The MOS 36-item Short-Form Health Survey (SF-36): III. Tests of data quality, scaling assumptions, and reliability across diverse patient groups. Med Care 1994:32:40-66.

18. Jones PW, Quirk FH, Baveystock CM. The St George's Respiratory Questionnaire. Respir Med 1991;85(Suppl B):25-31; discussion 3-7.

19. American Thoracic Society. Idiopathic pulmonary fibrosis: Diagnosis and treatment. International consensus statement. American Thoracic Society (ATS), and the European Respiratory Society (ERS). Am J Respir Crit Care Med 2000;161(2 Pt 1):646-64.

20. Bliven BD, Kaufman SE, Spertus JA. Electronic collection of health-related quality of life data: Validity, time benefits, and patient preference. Qual Life Res 2001;10:15-22.
21. Hays R, Sherbourne CD, Mazel RM, eds, In: User's Manual for Medical Outcomes Study (MOS) Core Measures of Health-Related Quality of Life (MR-162-RC). Santa Monica: RAND Corporation, 1995.

22. Wanger J, Clausen JL, Coates A, et al. Standardisation of the measurement of lung volumes. Eur Respir J 2005;26:511-22.

23. Macintyre N, Crapo RO, Viegi G, et al. Standardisation of the single-breath determination of carbon monoxide uptake in the lung. Eur Respir J 2005;26:720-35.

24. ATS statement: Guidelines for the six-minute walk test. Am J Respir Crit Care Med 2002;166:111-7.

25. Miller MR, Hankinson J, Brusasco V, et al. Standardisation of spirometry. Eur Respir J 2005;26:319-38.

26. Gaensler EA, Smith AA. Attachment for automated single breath diffusing capacity measurement. Chest 1973;63:136-45.

27. Morris JF, Temple WP, Koski A. Normal values for the ratio of one-second forced expiratory volume to forced vital capacity. Am Rev Respir Dis 1973;108:1000-3.

28. Ferrer M, Villasante C, Alonso J, et al. Interpretation of quality of life scores from the St George's Respiratory Questionnaire. Eur Respir J 2002;19:405-13.

29. Hsieh FY BD, Larsen MD. A simple method of sample size calculation for linear and logistic regression. Stat Med 1998;17:1623-34.

30. Hopman WM, Towheed T, Anastassiades T, et al. Canadian normative data for the SF-36 health survey. Canadian Multicentre Osteoporosis Study Research Group. CMAJ 2000;163:265-71.

31. Flaherty KR, Mumford JA, Murray S, et al. Prognostic implications of physiologic and radiographic changes in idiopathic interstitial pneumonia. Am J Respir Crit Care Med 2003;168:543-8.

32. Latsi PI, du Bois RM, Nicholson AG, et al. Fibrotic idiopathic interstitial pneumonia: The prognostic value of longitudinal functional trends. Am J Respir Crit Care Med 2003;168:531-7.

33. Lettieri CJ, Nathan SD, Barnett SD, Ahmad S, Shorr AF. Prevalence and outcomes of pulmonary arterial hypertension in advanced idiopathic pulmonary fibrosis. Chest 2006;129:746-52.

34. Raghu G, King TE Jr, Behr J, et al. Quality of life and dyspnoea in patients treated with bosentan for idiopathic pulmonary fibrosis (BUILD-1). Eur Respir J 2010;35:118-23.

35. Swigris JJ, Wamboldt FS, Behr J, et al. The 6 minute walk in idiopathic pulmonary fibrosis: Longitudinal changes and minimum important difference. Thorax 2010;65:173-7.

36. Swigris JJ, Brown KK, Behr J, et al. The SF-36 and SGRQ: Validity and first look at minimum important differences in IPF. Respir Med 2010;104:296-304. 


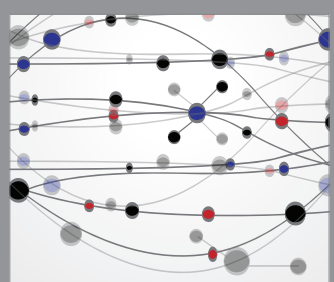

The Scientific World Journal
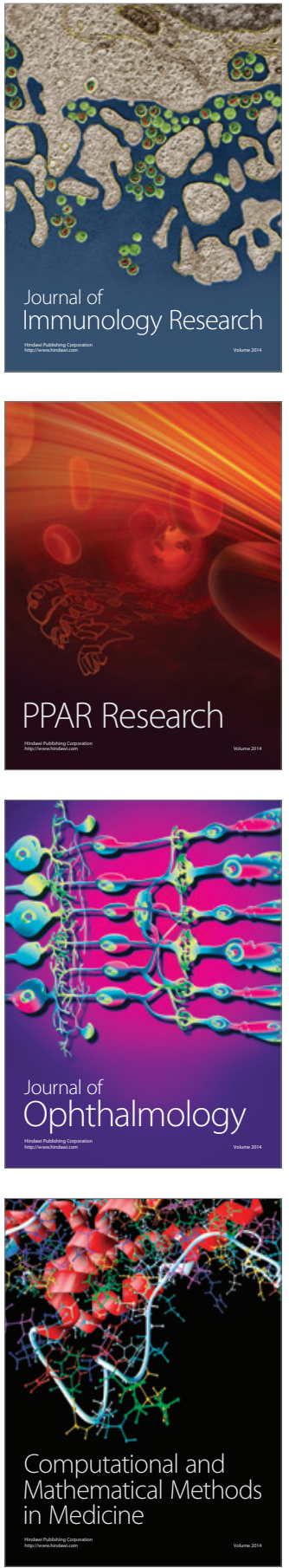

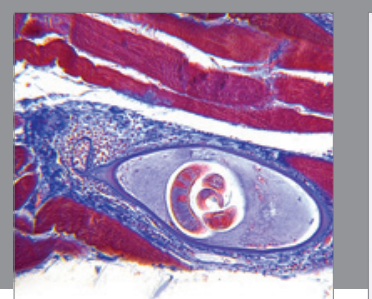

Gastroenterology Research and Practice

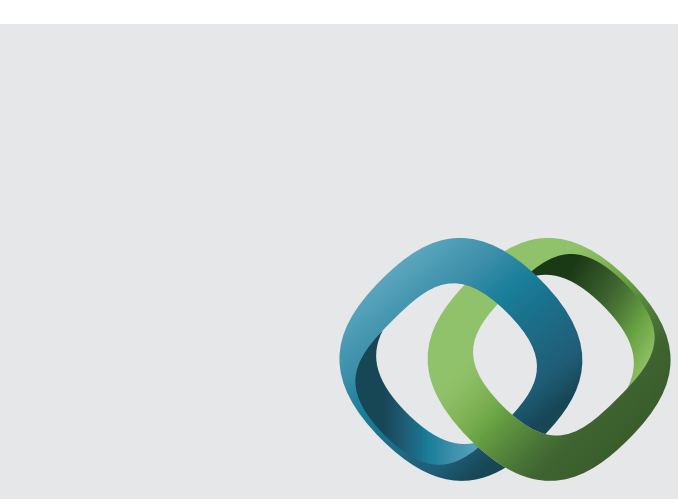

\section{Hindawi}

Submit your manuscripts at

http://www.hindawi.com
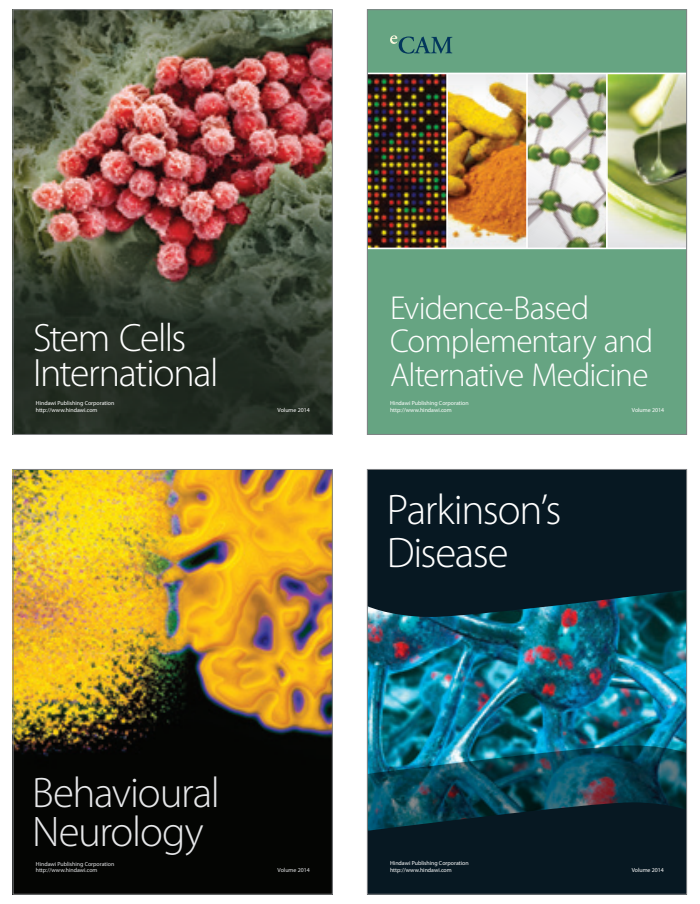
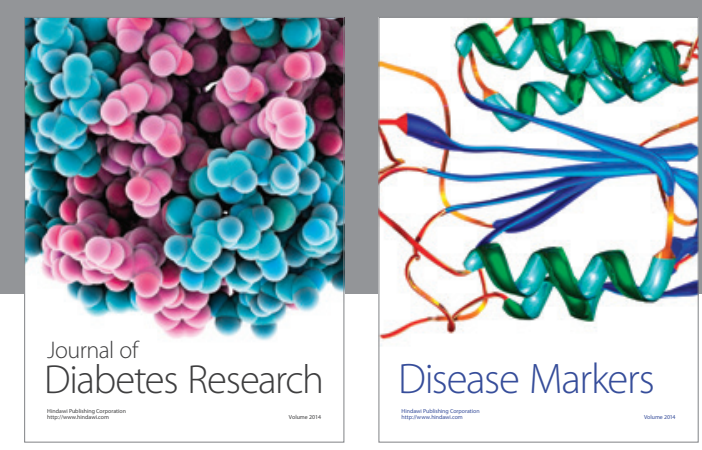

Disease Markers
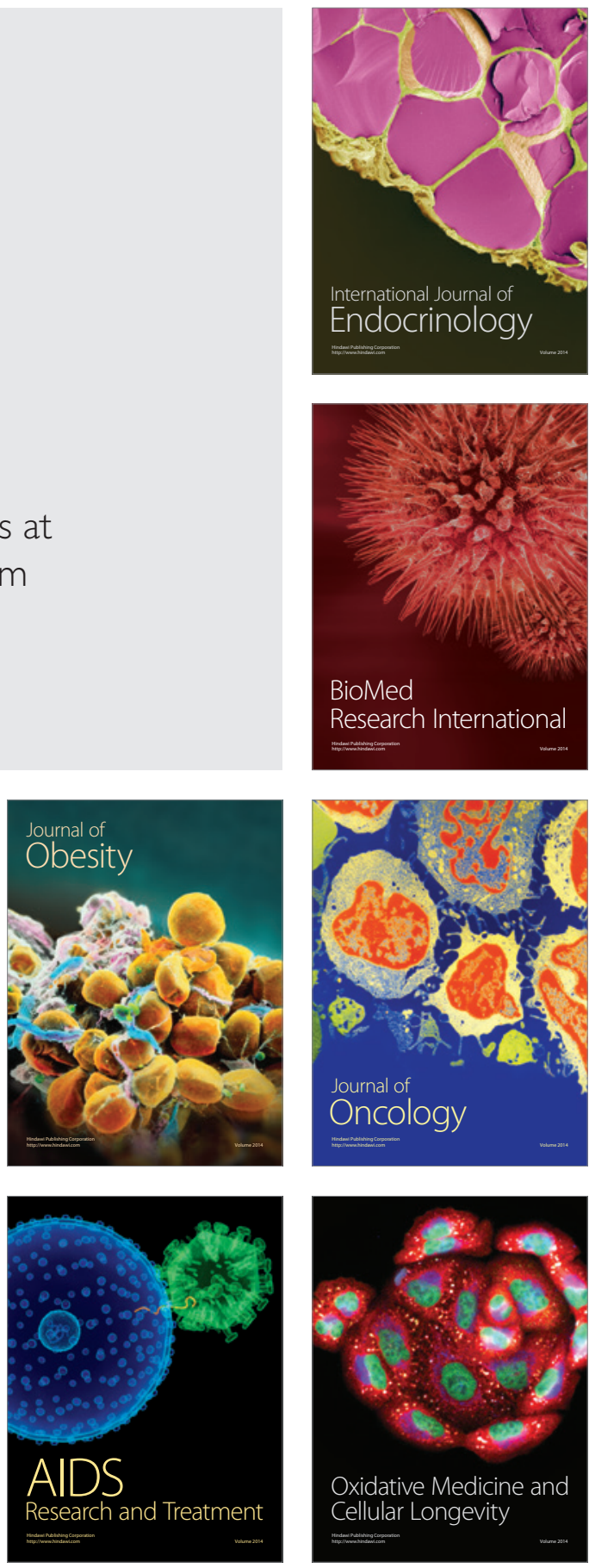